\title{
BMJ Open Use of healthcare services during the COVID-19 pandemic in urban Ethiopia: evidence from retrospective health facility survey data
}

\author{
Zemzem Shuka, ${ }^{1,2}$ Anagaw Mebratie, ${ }^{3}$ Getnet Alemu, ${ }^{1}$ Matthias Rieger, ${ }^{2}$ \\ Arjun S Bedi (i) ${ }^{2}$
}

To cite: Shuka Z, Mebratie A, Alemu G, et al. Use of healthcare services during the COVID-19 pandemic in urban Ethiopia: evidence from retrospective health facility survey data. BMJ Open 2022;12:e056745. doi:10.1136/ bmjopen-2021-056745

- Prepublication history and additional supplemental material for this paper are available online. To view these files, please visit the journal online (http://dx.doi.org/10.1136/ bmjopen-2021-056745).

Received 30 August 2021 Accepted 07 February 2022

Check for updates

(C) Author(s) (or their employer(s)) 2022. Re-use permitted under CC BY-NC. No commercial re-use. See rights and permissions. Published by BMJ.

${ }^{1}$ Institute of Development and Policy Research, Addis Ababa University, Addis Ababa, Oromia, Ethiopia

${ }^{2}$ International Institute for Social Studies, Erasmus Universiteit, Rotterdam, The Netherlands ${ }^{3}$ School of Public Health, Addis Ababa University, Addis Ababa, Oromia, Ethiopia

Correspondence to Dr Arjun S Bedi; bedi@iss.nl

\section{ABSTRACT}

Objectives In recent years, Ethiopia has made enormous strides in enhancing access to healthcare, especially, maternal and child healthcare. With the onset and spread of COVID-19, the attention of the healthcare system has pivoted to handling the disease, potentially at the cost of other healthcare needs. This paper explores whether this shift has come at the cost of non-Covid related healthcare, especially the use of maternal and child health (MCH) services.

Setting Data covering a 24-month period are drawn from 59 health centres and 29 public hospitals located in urban Ethiopia.

Primary and secondary outcomes measures The primary outcome measures are the use of $\mathrm{MCH}$ services including family planning, antenatal and postnatal care, abortion care, delivery and immunisation. The secondary outcome measures are the use of health services by adults including antiretroviral therapy (ART), tuberculosis (TB) and leprosy and dental services

Results There is a sharp reduction in the use of both inpatient $(20 \%-27 \%, p<0.001)$ and outpatient $(27 \%-34 \%$, $\mathrm{p}<0.001$ ) care, particularly in Addis Ababa, which has been most acutely affected by the virus. This decline does not come at the cost of $\mathrm{MCH}$ services. The use of several $\mathrm{MCH}$ components (skilled birth attendant deliveries, immunisation, postnatal care) remains unaffected throughout the period while others (family planning services, antenatal care) experience a decline $(8 \%-17 \%)$ in the immediate aftermath but recover soon after. Conclusion Concerns about the crowding out of $\mathrm{MCH}$ services due to the focus on COVID-19 are unfounded. Proactive measures taken by the government and healthcare facilities to ring-fence the use of essential healthcare services have mitigated service disruptions. The results underline the resilience and agility displayed by one of the world's most resource-constrained healthcare systems. Further research on the approaches used to mitigate disruptions is needed.

\section{INTRODUCTION}

In the past 20 years, Ethiopia has witnessed a sharp expansion in its public healthcare system. Between 2000 and 2019, there has been a 21-fold increase in the number of
Strengths and limitations of this study

- Analysis is based on data from multiple health facilities- 59 health centres and 29 public hospitals-located across the country which promotes generalisability.

- Study is based on retrospective health facility data covering a 2-year period which supports analysis of trends in healthcare use before-after onset of COVID-19 and year-on-year comparisons.

- Based on actual use of maternal and child health services as opposed to simulations of the effects of COVID-19 measures on healthcare use.

- Health management information systems data on certain variables is likely to be incomplete.

health posts, an 11-fold increase in the number of health centres and a 4-fold increase in the number of public hospitals. ${ }^{12}$ Per capita healthcare spending has grown from US $\$ 5.4$ in 2000 to US\$24.2 in 2018. ${ }^{3}$ Due to these efforts, access to essential healthcare services, as measured by the availability of health facilities within a 2-hour walking distance has increased from $51 \%$ in 2000 to $94 \%$ in $2016 .{ }^{45}$ In addition to access, the various interventions have been associated with increases in the use of mother and child health services and various health gains. $^{6-11}$ For instance, between 2000 and 2019 , the proportion of women receiving antenatal care (ANC) from a skilled provider at least once for their last birth increased from $27 \%$ to $74 \%$ while deliveries attended by skilled birth attendants (SBA) or in health facilities increased from $6 \%$ to $50 \%$ over the same duration.

These impressive gains have taken place in the context of a strengthening but still weak and under-resourced healthcare system. Compounding these issues, the onset and spread of the COVID-19 virus since March 
2020 and the need to pivot and equip the healthcare system towards tackling the virus has led to concerns about the sustainability of these hard-won gains in maternal and child health (MCH) outcomes. ${ }^{12} 13$ As in other countries, soon after the detection of the virus, Ethiopia went into a strict lockdown and the country's hospitals, especially in the capital were repurposed to treat virus affected patients with, potentially, adverse consequences for other healthcare needs. For instance, some public hospitals were designated as COVID-19 only hospitals and stopped provision of outpatient and inpatient services for nonCovid health issues. ${ }^{12} 14$ Other concerns included, absenteeism of healthcare personnel due to lack of safety equipment. ${ }^{15}$ On the demand side, the fear of contracting the virus and travel restrictions is likely to have translated into reductions in the use of antenatal and postnatal care (PNC) and an increase in non-institutional births.

Such concerns are not unique to Ethiopia. Disruptions to maternal and child healthcare services may translate into unintended pregnancies and increased maternal and child morbidity and mortality, especially in low-income countries. Based on simulations allowing for varying levels of disruption in access to MCH care and decreased access to food across 118 low-income and middle-income countries, there are projections of more than 200000 child deaths and 12000 maternal deaths in the least severe scenario. ${ }^{16}$ Similarly, based on the 37 countries, including Ethiopia, in which Marie Stopes International operates, there are projections of an additional 1.3 million unintended pregnancies and an additional 5000 pregnancy-related deaths. ${ }^{17}$ Based on telephone surveys, conducted during the period July to November 2020, in Addis Ababa, Ouagadougou and Lagos, $28 \%-39 \%$ of healthcare providers perceived reductions in provision of child healthcare. ${ }^{18}$

Whether dire predictions based on simulations ${ }^{16} 1719$ come to fruition in low-income countries such as Ethiopia or whether concerns such as health worker absenteeism, and reduced uptake of health services, which emerged soon after the imposition of virus-control measures are short-lived, is not yet clear. A search of the literature revealed no dearth of papers ${ }^{20-25}$ calling for attempts to protect the provision of $\mathrm{MCH}$ in low-income countries, particularly in sub-Saharan Africa (SSA) but evidence on prepandemic and postpandemic use of health services in Ethiopia and more generally in SSA was more limited.

Changes in health service utilisation using countrywide health management information systems (HMIS) data from 8 SSA countries (Cameroon, Democratic Republic of Congo, Liberia, Malawi, Mali, Nigeria, Sierra Leone and Somalia) has been used to analyse the effect of COVID-19 on the use of MCH services. ${ }^{26}$ The analysis shows that outpatient consultations and child vaccinations were the most vulnerable services while decreases in maternal healthcare were less generalised. For instance, between March and July 2020, the use of outpatient services declined from a low of $1 \%$ in Somalia to a high of $16 \%$ in Nigeria. Except for the DRC, vaccination shots
(Pentavalent 3) fell between 2\% in Cameroon to $17 \%$ in Mali. Although, not universal, the declines were most acute in April-May with a reversal in June-July. Single country analysis of changes in access to $\mathrm{MCH}$, which perhaps allows for deeper exploration are also available. ${ }^{2728}$ HMIS data from Rwanda shows that the use of 15 of $30 \mathrm{MCH}$ services declined between March-April 2019 and March-April 2020. ${ }^{27}$ Analysis based on HMIS data from South Africa's KwaZulu Natal province and a prepost comparison yields sharp and significant declines in clinic attendance $(36 \%)$ and hospital admissions (50\%) for children aged less than 5 years in the period AprilJune $2020 .^{28}$

There is also an emerging body of work in the Ethiopian context. A comparison of MCH use between MarchJuly 2020 and March-July 2019 in 15 health centres in rural Ethiopia finds modest declines in key MCH and nutrition services which are pronounced in March and April and recover, thereafter. ${ }^{29}$ However, since the main effect of the pandemic was in urban Ethiopia a focus on rural parts is likely to underestimate the consequences. Analysis of data gathered from 31 health centres and four hospitals located in SNNP (Southern Nations, Nationalities, and People's) Region region displays reduction in the use of ANC, health facility births, PNC, family planning visits and newborn immunisation services with the effect ranging from $16 \%$ to $29 \%$. There is evidence of an uptake in services in May and June 2020 after reductions in March and April 2020. ${ }^{30}$ In terms of the incidence of COVID-19 cases, in August 2020, the region accounted for $1.6 \%$ of the cases in the country. Closest to the current contribution is a study which examines changes in healthcare use between November 2019 and June 2020 in nine health facilities located in Addis Ababa, the region most acutely affected by the virus. ${ }^{14}$ The study reports a $25 \%$ reduction in inpatient care and a $42 \%$ reduction in outpatient visits. In marked contrast the use of MCH services yields a more sanguine picture with the use of ANC1, ANC4, Penta1, Penta4 vaccinations and the use of SBA displaying no declines before and during COVID-19.

This paper contributes to the body of work on the effects of COVID-19 on actual use of health services in SSA and in particular in Ethiopia. Such evidence is clearly needed to identify vulnerabilities in the healthcare system and more importantly to support the continued provision of essential services to protect hard won gains in maternal and child mortality. This paper responds to such concerns and uses data culled from the HMIS of 88 health facilities located in four regional states of urban Ethiopia, as opposed to just a single region, to compare healthcare use in the 4 months (March-June 2020) immediately after the identification of the first case of the virus in the country with healthcare use a year before (March-June 2019) and the 4 months just preceding March 2020 (November 2019-February 2020). The paper examines changes in the use of both inpatient and outpatient care and thereafter focuses on the use of a range of MCH services. Since a key supply-side concern is the 


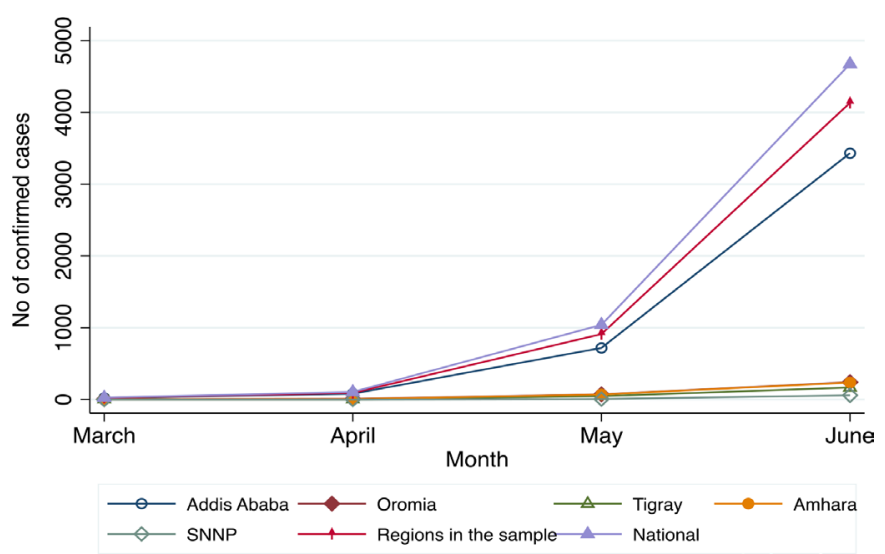

Figure 1 Monthly COVID-19 cases in Ethiopia, March to June 2020. SNNP, Southern Nations, Nationalities, and People's region

availability of healthcare services during the pandemic, we also examine infection prevention measures undertaken by the facilities, and most pertinently health worker absenteeism before and after March 2020.

\section{DATA AND METHODS \\ Data}

This study is based on a retrospective cross sectional health facility survey, conducted through phone and internet, which covered four regional states (Tigray, Amhara, Oromia and SNNP) and Addis Ababa city administration. Together, these regions account for $89.5 \%$ of the country's population $^{31}$ and $85.6 \%$ of the COVID-19 cases in the country as per 16 August 2020 - the date that data collection commenced. ${ }^{32}$

Ethiopia confirmed its first COVID-19 case on 13 March 2020 and data collection took place between August and December 2020. At the time of commencing data collection, the bulk of the facilities had collected and validated data up to the end of June 2020 and so for the postcovid period we focused on the 4-month period from March to June 2020. To enable immediate before-after comparisons we gathered information for the 4-month period just prior to COVID-19, that is, November 2019 to February
2020. To avoid seasonal effects, we also gathered data on healthcare use in the 4-month period between March and June 2019. In addition to these 12 months, to enhance longer-term comparisons and avoid criticisms that the time periods have been purposively chosen to augment differences, we collected information for a period of 24 months-that is, July 2018 to June 2020.

The plan was to cover 60 health centres and 30 public hospitals while the survey actually covered 59 health centres and 29 hospitals. The regional distribution of the sample was guided by the regional distribution of COVID-19 cases in the country at the end of June 2020 (see figure 1 and table 1). Based on these considerations, the bulk of the sampled facilities were in Addis Ababa which accounted for $73 \%$ of COVID-19 cases in June 2020, followed by Oromia (5.6\%). There are 91 health centres in Addis Ababa and 44 were randomly chosen for the survey. The city has 12 public hospitals of which 11 were included in the survey (see table 1). Indeed, not only are a majority of the sampled facilities located in Addis Ababa (table 1) but over $60 \%$ provide care for COVID-19 infected patients (see online supplemental table A1).

After ensuring that a health facility was willing to participate in the survey, a survey instrument was sent by email to health facility ICT (Information and Communication Technology) workers responsible for facility HMIS. To ensure data quality, discussions to clarify concerns took place with ICT workers throughout the data collection and data cleaning process. From the HMIS, information was culled on monthly inpatient and outpatient visits for 24 months (July 2018 till June 2020). In addition to the total visits, data were collected on specific outpatient services including the gamut of maternal and childcare health services (family planning services (FPS), ANC, abortions, delivery, PNC, immunisation, integrated management of neonatal and childhood illnesses (IMNCI), prevention of mother-to-child HIV transmission care (PMTCT).

The survey also included modules to ascertain the level of preparedness and provision of COVID-19-related services, provision of supplies such as personal protective equipment (PPE), measures taken to mitigate the spread of COVID-19 and challenges faced by facilities due to

\begin{tabular}{|c|c|c|c|c|c|}
\hline Region & $\begin{array}{l}\text { CoVID-19 cases } \\
\text { June } 2020, \mathrm{~N}\end{array}$ & $\begin{array}{l}\text { Share of region in total } \\
\text { cases }(\%)\end{array}$ & Health centres & Public hospitals & Total \\
\hline Addis Ababa & 4250 & 72.7 & 44 & 11 & 55 \\
\hline Oromia & 325 & 5.6 & 7 & 8 & 15 \\
\hline Tigray & 213 & 3.6 & 3 & 5 & 8 \\
\hline Amhara & 312 & 5.3 & 3 & 3 & 6 \\
\hline SNNP & 63 & 1.1 & 2 & 2 & 4 \\
\hline Total & 5163 & 88.3 & 59 & 29 & 88 \\
\hline
\end{tabular}

Source: COVID figures are from the National Public Health Emergency Operation Center COVID-19 Situation Reports no. 68, 98, $129,158$. The total number of confirmed cases in the country at the end of June 2020 was 5846.

SNNP, Southern Nations, Nationalities, and People's region. 
Table 2 Inpatient and outpatient healthcare use

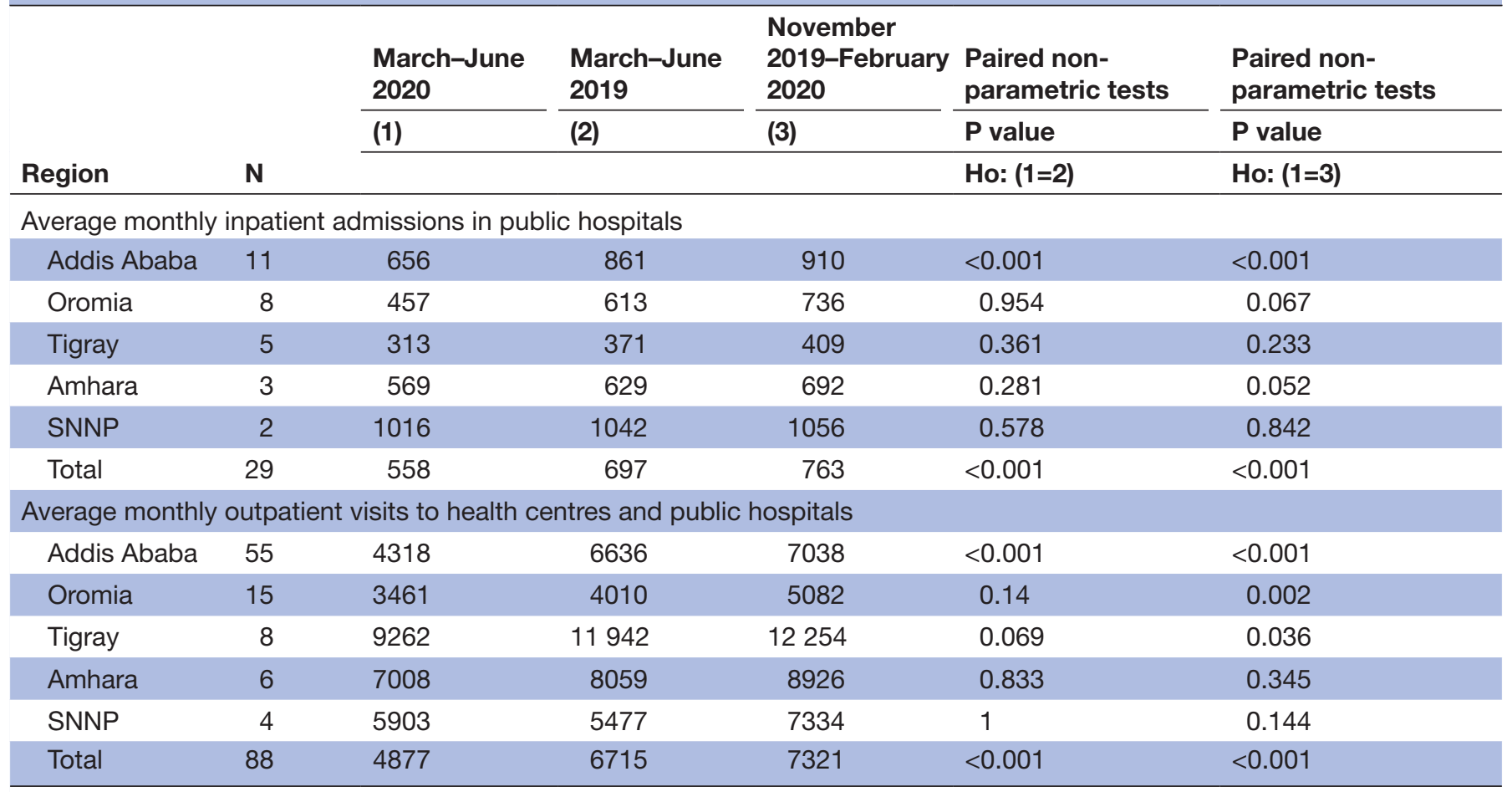

A Bonferroni-corrected $p$ value of $0.003(0.05 / 15)$ is used to interpret results.

SNNP, Southern Nations, Nationalities, and People's region.

the virus, especially related to absenteeism of healthcare professionals and support staff. Information on facilitylevel preparations to deal with COVID-19 was provided by facility directors while information on absenteeism was provided by facility human resources officers.

\section{Methods}

Graphs, descriptive statistics and paired non-parametric (Wilcoxon signed-rank) tests of significance which do not assume that the differences between paired samples is normally distributed are used to compare levels of inpatient and outpatient healthcare service utilisation (number of patients per month) before and after the onset and spread of the virus. The analysis of outpatient visits includes data from health centres and public hospitals while inpatient care utilisation is restricted to data from public hospitals as health centres mainly provide outpatient services. In addition to the total visits for healthcare, we also compare the number of visits for different types of mother and child health services such as family planning, ANC, abortion, delivery, PNC, immunisation, IMNCI, PMTCT. we assess absenteeism of hospital staff by comparing the number of staff members that should be in the hospital and the number of staff members that were present on the day of the survey. we test for temporal changes in 14 types of healthcare use and absenteeism. To avoid pitfalls associated with multiple-hypothesis testing, we interpret results, tables 2-5, keeping in mind the Bonferroni correction-that is, we use a $p$ value of 0.003
$(0.05 / 15)$ to draw inferences rather than the conventional $5 \%$ level of significance.

Although we have 2 years of utilisation data, the focus is on the 4-month period, March to June 2020 as compared with healthcare use in the 4-month period March to June 2019. Comparing service use volumes for similar months, as opposed to before and after March 2020, helps to account for seasonal variations in patient flows. ${ }^{33}$ However, to account for the possibility that yearon-year comparisons may underestimate the extent of the decline, if there is an increase in healthcare utilisation over time, we also compare healthcare use between the 4-month period, March to June 2020 with the 4-month period, November 2019 to February 2020, which precedes the first COVID-19 case in Ethiopia. Additionally, graphs are used to demonstrate year-on-year changes in healthcare use, that is, comparing healthcare use, per month, over the period July 2019-June 2020 to the period July 2018-June 2019.

\section{Public involvement}

The research questions were developed based on conversations with and concerns about declines in non-Covid healthcare use and health worker absenteeism expressed by healthcare providers in the country's largest hospital located in Addis Ababa. Suggestions on appropriate comparison periods and the type of healthcare services to be investigated were provided by managers of healthcare facilities. The results have been discussed with and 
Table 3 Mother and child healthcare use-prebirth and delivery average monthly visits

\begin{tabular}{|c|c|c|c|c|c|c|}
\hline & & $\begin{array}{l}\text { March-June } \\
2020 \\
\end{array}$ & $\begin{array}{l}\text { March-June } \\
2019\end{array}$ & $\begin{array}{l}\text { November 201- } \\
\text { February } 2020 \\
\end{array}$ & $\begin{array}{l}\text { Paired non- } \\
\text { parametric tests }\end{array}$ & $\begin{array}{l}\text { Paired non- } \\
\text { parametric tests }\end{array}$ \\
\hline & & (1) & (2) & (3) & $P$ value & $P$ value \\
\hline Region & $\mathbf{N}$ & & & & Ho: $(1=2)$ & Ho: $(1=3)$ \\
\hline \multicolumn{7}{|c|}{ Family planning services } \\
\hline Addis Ababa & 54 & 63 & 71 & 73 & 0.005 & $<0.001$ \\
\hline Oromia & 15 & 66 & 56 & 69 & 0.532 & 0.233 \\
\hline Tigray & 8 & 93 & 125 & 131 & 0.124 & 0.036 \\
\hline Amhara & 6 & 149 & 158 & 154 & 0.249 & 0.917 \\
\hline SNNP & 4 & 76 & 71 & 107 & 1 & 0.465 \\
\hline Total & 87 & 73 & 79 & 85 & 0.009 & $<0.001$ \\
\hline \multicolumn{7}{|l|}{ Antenatal care } \\
\hline Addis Ababa & 55 & 170 & 175 & 185 & 0.393 & 0.001 \\
\hline Oromia & 15 & 145 & 162 & 174 & 0.118 & 0.027 \\
\hline Tigray & 8 & 207 & 307 & 340 & 0.182 & 0.012 \\
\hline Amhara & 6 & 153 & 185 & 196 & 0.345 & 0.028 \\
\hline SNNP & 4 & 177 & 162 & 151 & 0.715 & 0.715 \\
\hline Total & 88 & 168 & 185 & 197 & 0.053 & $<0.001$ \\
\hline \multicolumn{7}{|l|}{ Abortion care } \\
\hline Addis Ababa & 53 & 13 & 16 & 17 & 0.088 & 0.001 \\
\hline Oromia & 14 & 12 & 17 & 18 & 0.03 & 0.02 \\
\hline Tigray & 8 & 22 & 27 & 34 & 0.674 & 0.124 \\
\hline Amhara & 5 & 24 & 27 & 26 & 0.5 & 0.753 \\
\hline SNNP & 4 & 19 & 22 & 27 & 0.465 & 0.068 \\
\hline Total & 84 & 15 & 18 & 20 & 0.036 & $<0.001$ \\
\hline \multicolumn{7}{|l|}{ Delivery } \\
\hline Addis Ababa & 50 & 145 & 135 & 129 & 0.052 & 0.027 \\
\hline Oromia & 15 & 160 & 154 & 150 & 0.865 & 0.256 \\
\hline Tigray & 7 & 197 & 192 & 189 & 0.612 & 0.028 \\
\hline Amhara & 6 & 195 & 185 & 187 & 0.035 & 0.173 \\
\hline SNNP & 3 & 164 & 178 & 215 & 0.109 & 0.144 \\
\hline Total & 81 & 157 & 148 & 146 & 0.044 & $<0.001$ \\
\hline
\end{tabular}

A Bonferroni-corrected $p$ value of $0.003(0.05 / 15)$ is used to interpret results.

SNNP, Southern Nations, Nationalities, and People's region.

corroborated by healthcare workers at two large hospitals in Addis Ababa.

\section{RESULTS}

Our discussion of the results begins by examining changes in the use of in-patient care, followed by commentary on out-patient care and its various components.

\section{Inpatient care use}

Changes in the use of inpatient care are displayed in table 2 and figure 2. On average, per month, between March and June 2020, there were 558 inpatient admissions to the 29 hospitals. This is a $20 \%$ decline as compared with the 697 admissions a year ago and a 27\% decline as compared with the 4-month period preceding March 2020. Regardless of the comparison period the reduction is statistically significant $(p<0.001)$. Based on a year-on-year comparison, the declines are greater in the regions most affected by the virus, that is, Addis Ababa and Oromiya which experience declines of about $24 \%-26 \%$ as compared with other parts of the country which experience smaller (16\% in Tigray; $9.5 \%$ in Amhara) or no declines (SNNP). Year-on-year monthly comparisons (figure 1) over the period show a $30 \%$ decline in inpatient admissions between April 2020 and April 2019. However, there are clear signs of recovery in May and June 2020. 
Table 4 Mother and child healthcare use-postbirth average monthly visits

\begin{tabular}{|c|c|c|c|c|c|c|}
\hline & & $\begin{array}{l}\text { March-June } \\
2020\end{array}$ & $\begin{array}{l}\text { March-June } \\
2019\end{array}$ & $\begin{array}{l}\text { November 2019- } \\
\text { February } 2020\end{array}$ & $\begin{array}{l}\text { Paired non- } \\
\text { parametric tests }\end{array}$ & $\begin{array}{l}\text { Paired non- } \\
\text { parametric tests }\end{array}$ \\
\hline & & (1) & (2) & (3) & $P$ value & $P$ value \\
\hline Region & $\mathbf{N}$ & & & & Ho: (1=2) & Ho: (1=3) \\
\hline \multicolumn{7}{|l|}{ Postnatal care } \\
\hline Addis Ababa & 51 & 97 & 92 & 107 & 0.339 & 0.777 \\
\hline Oromia & 15 & 169 & 150 & 161 & 0.32 & 0.148 \\
\hline Tigray & 6 & 92 & 77 & 96 & 0.249 & 0.672 \\
\hline Amhara & 6 & 85 & 75 & 99 & 0.248 & 0.345 \\
\hline SNNP & 4 & 184 & 171 & 149 & 0.715 & 0.198 \\
\hline Total & 82 & 113 & 104 & 118 & 0.053 & 0.796 \\
\hline \multicolumn{7}{|l|}{ Immunisation } \\
\hline Addis Ababa & 52 & 598 & 576 & 639 & 1 & 0.008 \\
\hline Oromia & 15 & 592 & 714 & 617 & 0.955 & 0.394 \\
\hline Tigray & 6 & 1376 & 1415 & 1591 & 0.6 & 0.249 \\
\hline Amhara & 6 & 656 & 501 & 583 & 0.173 & 0.345 \\
\hline SNNP & 4 & 664 & 643 & 732 & 0.715 & 0.273 \\
\hline Total & 83 & 661 & 660 & 704 & 0.744 & 0.006 \\
\hline \multicolumn{7}{|c|}{ Prevention of mother-to-child HIV transmission care } \\
\hline Addis Ababa & 51 & 69 & 85 & 87 & 0.001 & $<0.001$ \\
\hline Oromia & 11 & 119 & 131 & 122 & 0.05 & 0.168 \\
\hline Tigray & 8 & 93 & 133 & 140 & 0.093 & 0.05 \\
\hline Amhara & 6 & 133 & 145 & 168 & 0.917 & 0.249 \\
\hline SNNP & 4 & 168 & 179 & 167 & 0.715 & 0.713 \\
\hline Total & 80 & 88 & 105 & 107 & $<0.001$ & $<0.001$ \\
\hline \multicolumn{7}{|c|}{ Integrated Management of Neonatal and Childhood IIIness care } \\
\hline Addis Ababa & 7 & 273 & 462 & 525 & 0.022 & 0.022 \\
\hline Oromia & 6 & 205 & 229 & 191 & 0.249 & 0.612 \\
\hline Tigray & 8 & 309 & 242 & 444 & 0.246 & 0.03 \\
\hline Amhara & 5 & 254 & 326 & 310 & 0.893 & 0.08 \\
\hline SNNP & 2 & 49 & 71 & 63 & 0.18 & 0.18 \\
\hline Total & 28 & 249 & 297 & 353 & 0.118 & $<0.001$ \\
\hline
\end{tabular}

A Bonferroni-corrected $p$ value of $0.003(0.05 / 15)$ is used to interpret results. SNNP, Southern Nations, Nationalities, and People's region.

\section{Outpatient care use}

With regard to the use of outpatient care (table 2), the average monthly outpatient visits to sampled facilities between March and June 2020 was 4877 while the corresponding figure between March and June 2019 was 6715 or a decline of $27 \%(\mathrm{p}<0.001)$. As compared with the 4 months immediately preceding March 2020, the decline in usage is more pronounced $(34 \%, \mathrm{p}<0.001)$. Based on a year-on-year comparison, the decline in Addis Ababa is $35 \%$ while it is about $39 \%$ based on comparing usage rates just prior to March 2020. As in the case of inpatient services the decline is larger in Addis Ababa as compared with other regions which experience smaller declines $(14 \%, 22 \%$ and $13 \%$ in Oromia, Tigray and Amhara, respectively) or even a modest increase (SNNP). Year-onyear monthly comparisons (figure 2) shows a $40 \%$ decline in healthcare use between March and April 2020 which begins to pick up in May and June 2020 but unlike inpatient care the uptick is much lower and throughout May and June 2020 the number of outpatient visits remains below the pre-pandemic period.

Utilisation by type of service: prebirth and delivery

Given the decline in the use of both outpatient and inpatient care health use a key concern is whether usage of MCH services has been affected. Table 3 examines changes in the use of family planning services, ANC, abortions and deliveries. 
Table 5 Utilisationof various health services by adults average monthly visits

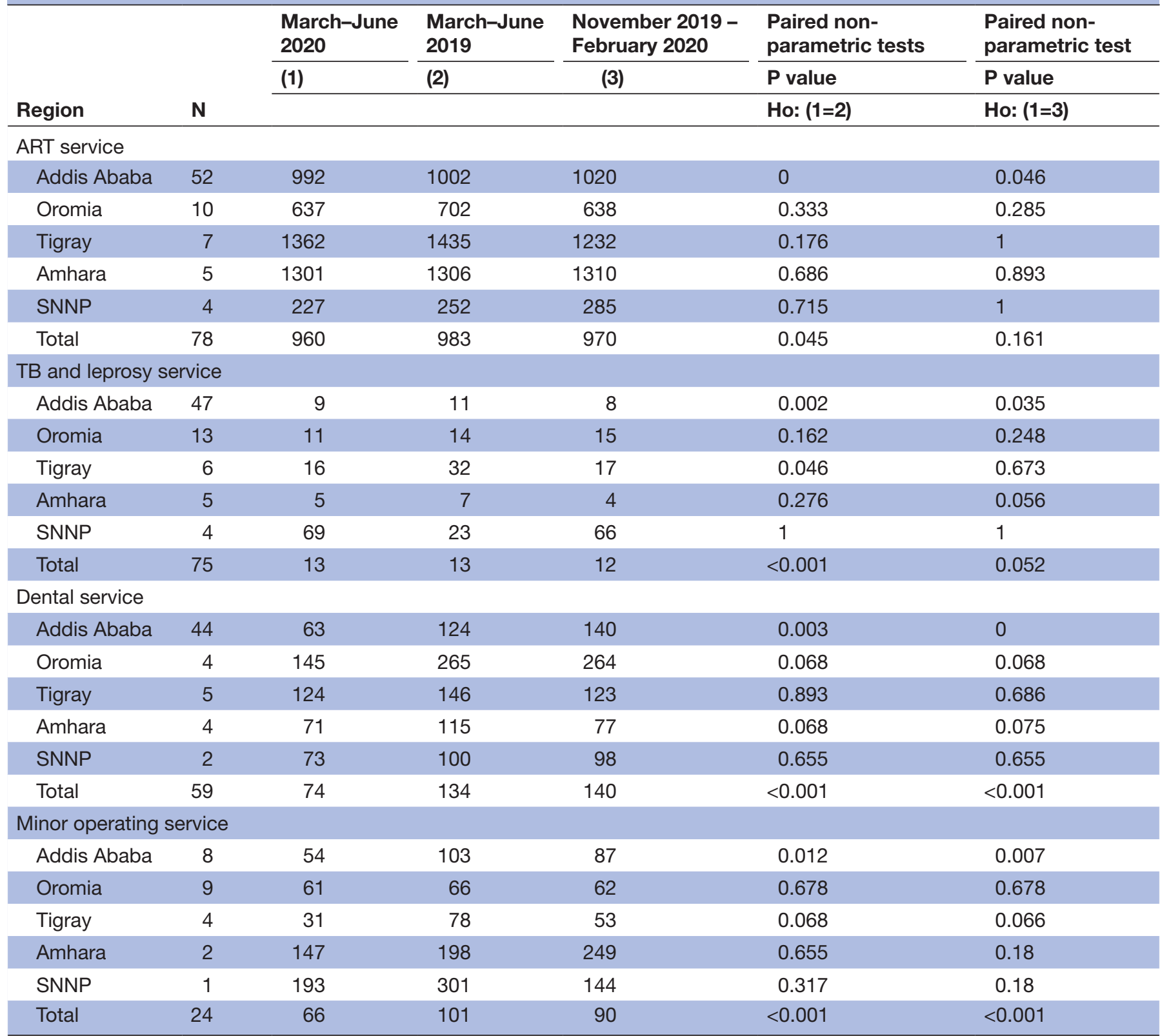

A Bonferroni-corrected $p$ value of $0.003(0.05 / 15)$ is used to interpret results.

ART, antiretroviral therapy; SNNP, Southern Nations, Nationalities, and People's region; TB, tuberculosis.

There is an $8 \%$ statistically insignificant decline in the use of family planning services between March-June 2020 and March-June 2019. There is a 16\% decline $(\mathrm{p}<0.001)$ in the use of family planning services between March-June 2020 and the period immediately preceding the onset of COVID-19 in the country. There is a similar pattern with regard to the use of antenatal services. That is, a $9 \%$ statistically insignificant $(\mathrm{p}=0.053)$ decline based on a year-on-year comparison while the decline based on a comparison with the preceding period is $17 \%$ and statistically significant $(p<0.001)$. Although the numbers are small in absolute terms, the use of health facilities for abortion care declines by about $16 \%$ based on a yearon-year comparison and by $25 \%$ as compared with the period November 2019-February 2020. With regard to deliveries, there are no changes over time, if anything, post-March 2020, there is an increase in the number of deliveries taking place at health facilities. Decomposing the overall change into monthly comparisons shows that declines in the use of FPS and ANC reach their nadir in March and April but recover to prepandemic levels in May and June. In contrast, the use of health services for abortions continues to decline post-March 2020 (figure 3A,B).

\section{Utilisation by type of service: postbirth}

The use of health facilities for PNC remains stable regardless of the reference period used for comparison (table 4). Similarly, the use of immunisation services 


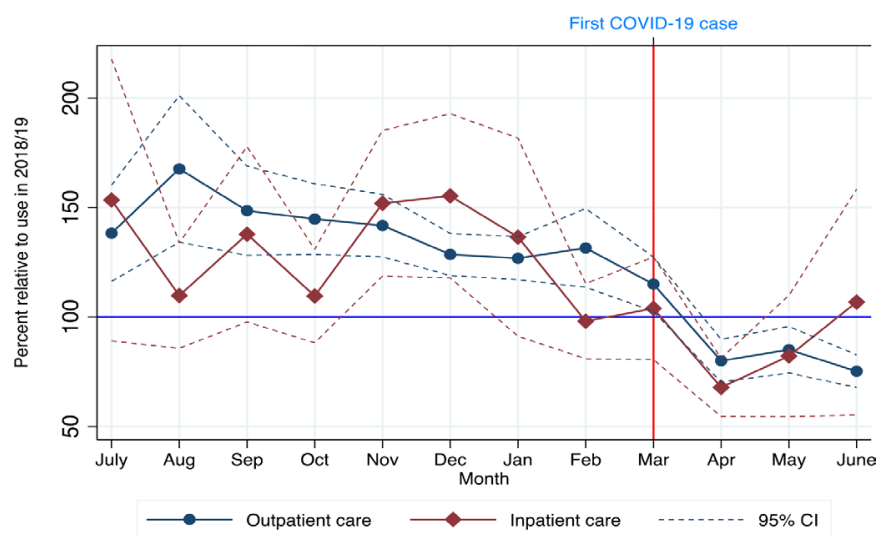

Figure 2 Volume of healthcare use in 2019/20 relative to same month in 2018/2019.

does not seem to have experienced a major disruption. There is no change on the basis of year-on-year comparisons while there is a statistically insignificant decline $(6 \%$, $\mathrm{p}=0.006$ ) as compared with usage during the November 2019-February 2020 period with Addis Ababa experiencing the largest decline $(10 \%)$. The disruption is

A

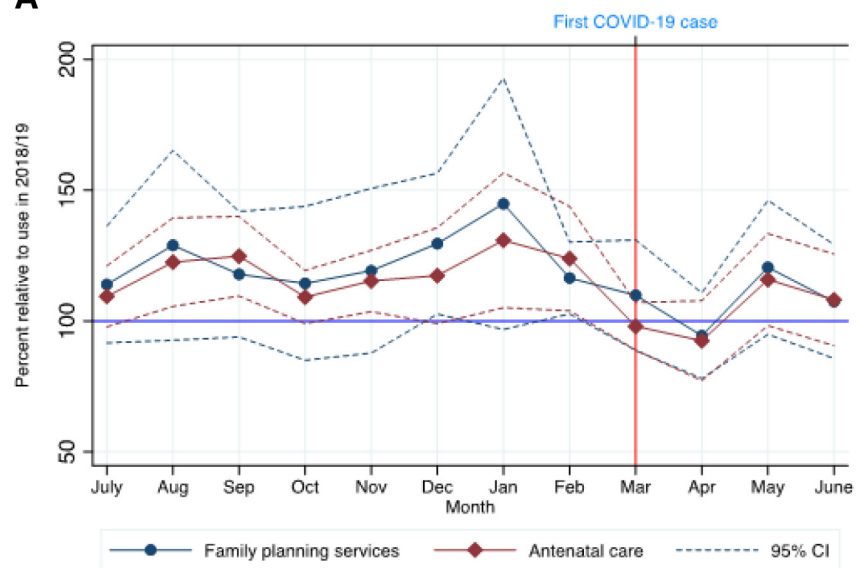

B

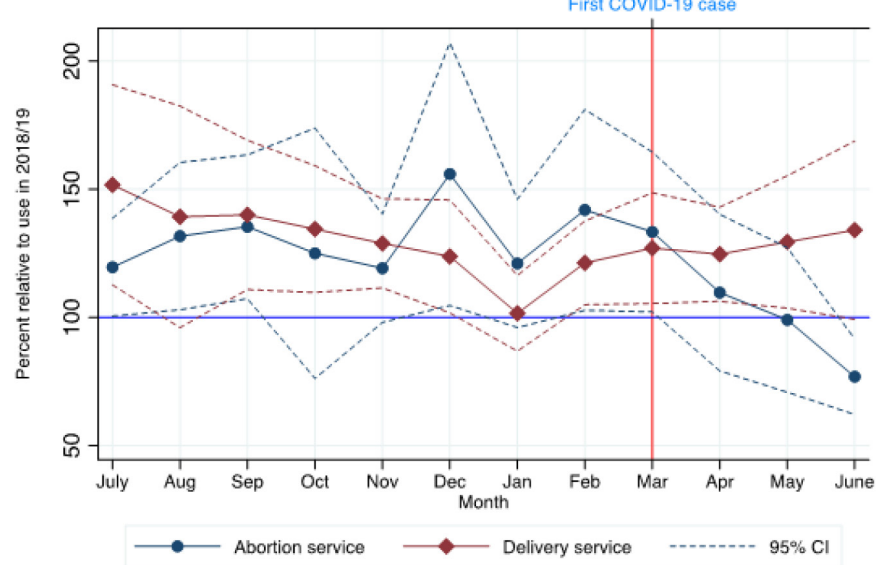

Figure 3 Volume of family planning services, ANC visits, abortion and delivery service use in $2019 / 20$ relative to same month in 2018/2019. ANC, antenatal care.
A

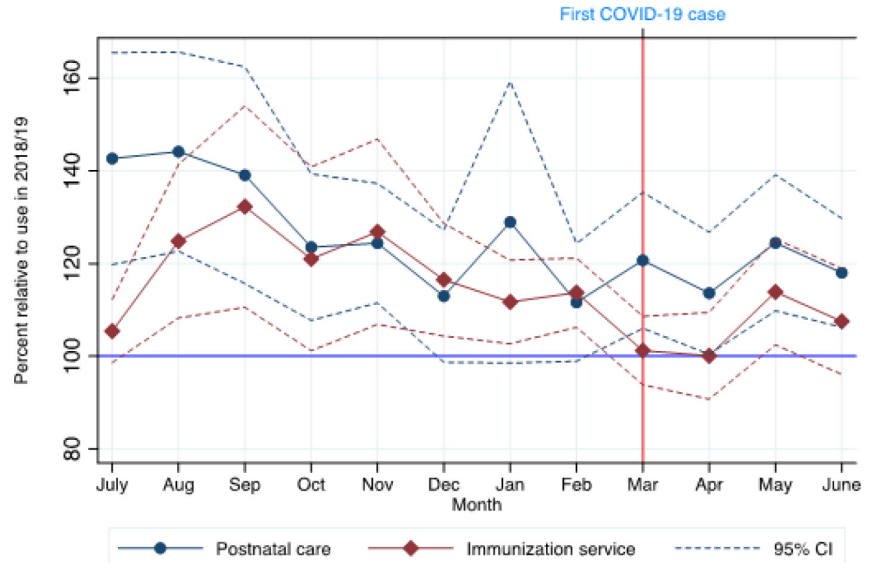

B

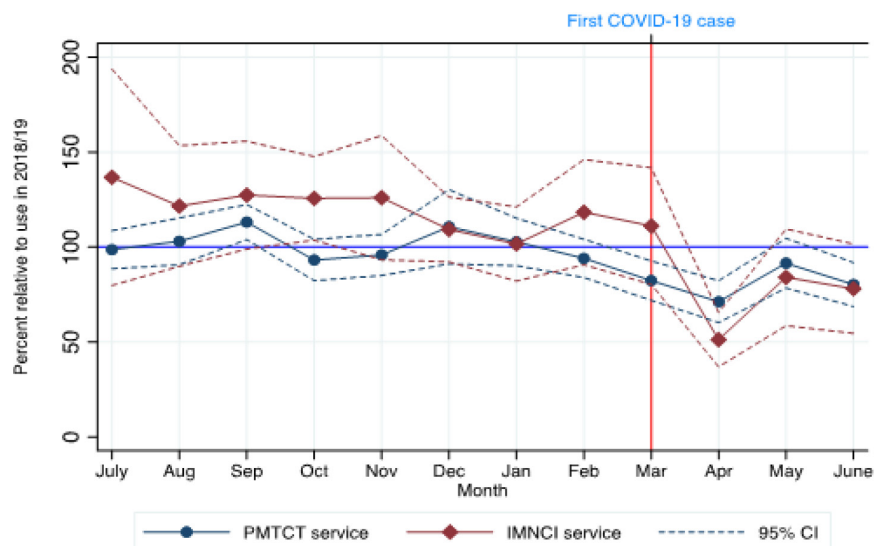

Figure 4 Volume of PNC, immunisation service, PMTCT and IMNCI service use in 2019/2020 relative to same month in $2018 / 2019$. IMNCl, integrated management of neonatal and childhood illnesses; PMTCT, prevention of mother-to-child HIV transmission care; PNC, postnatal care.

largest in March 2020 but it is short-lived and by MayJune 2020 the use of such services recovers to prepandemic levels. While PNC and immunisation appear to be protected, there is a decline in the use of health services for PMTCT care of between $16 \%$ and $18 \%$ depending on the reference period under consideration. The effects are even larger for IMNCI care which experiences reductions of $16 \%-29 \%$, depending on the reference period. However, there are signs of recovery in May and June 2020 , although use rates remain at about $90 \%$ of prepandemic levels (figure 4A,B).

\section{Utilisation of non-MCH health services}

Table 2 and figure 2 show clear declines in the use of healthcare services for both inpatient and outpatient care. Analysis of the different components of care shows that the decline in $\mathrm{MCH}$ services is not very pronounced, suggesting that the decline in healthcare usage comes from foregoing, postponing or substituting in-person hospital visits with alternative forms of care. While we do not have detailed information on all components of nonMCH care, the data we do have reveals a clear pattern. 
A

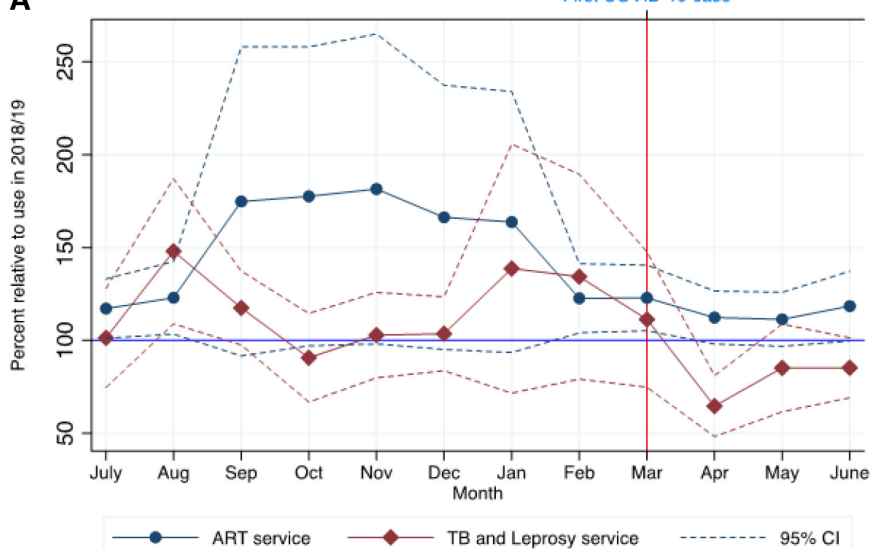

B

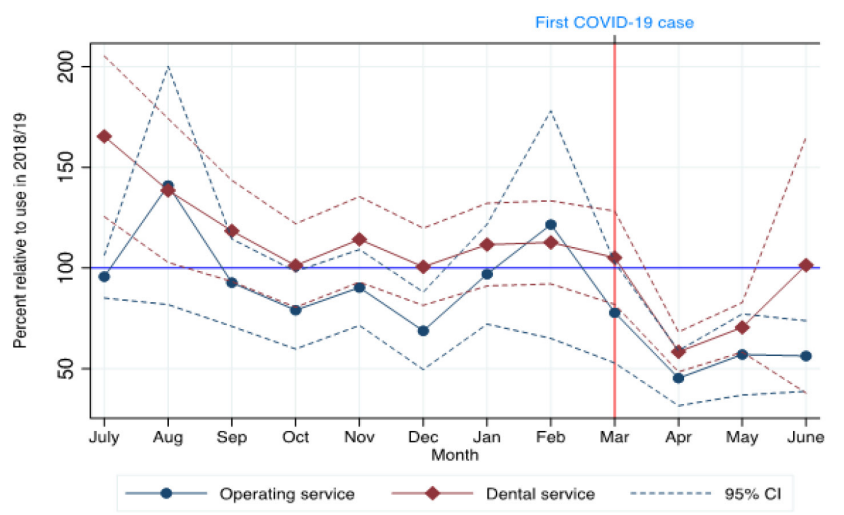

Figure 5 Volume of ART, TB and leprosy, operating and dental service use in 2019/2020 relative to same month in 2018/2019. ART, antiretroviral therapy; TB, tuberculosis.

The data show that the use of health facilities for essential (ART, TB services) non-MCH care continues unabated (see table 5 and figure 5A,B), however, dental services and minor operating procedures show statistically significant deadlines $(p<0.001)$ declines. The use of health facilities for dental care drops by $45 \%$ and for minor operations by $35 \%$ on a year-on-year basis.

\section{Infection prevention measures and health worker absenteeism}

Key concerns driving the demand for healthcare utilisation as well as health worker and support staff absenteeism is the extent to which facility are geared towards preventing infection and have the equipment to do so. Our data show that all health facilities received additional equipment such as thermometers, face masks and gloves, while about $70 \%$ received full PPE kits (suits, boots, face shades, goggles). Consistent with government guidelines, almost all the facilities in our sample introduced a range of infection prevention measures (see online supplemental table A2). While health worker absenteeism seems to have increased during this time period $(p<0.001)$, it is not particularly high in absolute terms (about $7 \%$, see online supplemental table A3). Based on direct questions to facility managers, absenteeism of health worker staff was rated as an issue in the case of about $8 \%$ of the facilities in our sample. While there were several reasons for absenteeism the most prominent were that staff were on sanctioned leave, were on COVID-19 duty elsewhere or were unwell, including due to the virus.

\section{DISCUSSION}

This paper analysed the effect of COVID-19 on the use of a range of healthcare services in Ethiopia. Key strengths include analysis of data from multiple health facilities located across the country which promotes generalisability and the use of data covering a 2-year period which supports both analysis of trends in healthcare use before and after the onset of COVID-19 and year-on-year comparisons. The simple 'before-and-after' design is appropriate for sharp and relatively unexpected events and for high frequency data, as is the case here while the year-onyear comparison accounts for seasonal effects. Furthermore, the study was based on actual use of MCH services as opposed to simulations of the effects of COVID-19 measures on healthcare use.

There is a clear and sharp decline in the use of both inpatient and outpatient services after the onset of COVID-19 in Ethiopia. Depending on the reference period the decline in inpatient care ranged between $20 \%$ and $27 \%$. The decline in outpatient care is somewhat higher and ranges between $27 \%$ and $34 \%$. The overall decline in the use of health services and the focus on treating COVID-19 has sparked concerns about maternal and child healthcare outcomes. ${ }^{161719}$ Motivated by these concerns, this study focused on MCH services. The analysis showed that unlike the sharp declines in overall use of health services, declines for several components of MCH care were lower and recovery was faster. For instance, with regard to $\mathrm{MCH}$ services, the use of FPS and ANC declined between $8 \%$ and $18 \%$ but there was no change in the use of healthcare facilities for deliveries, PNC and for immunisation. These patterns belie concerns about losing hard-won gains in maternal and healthcare outcomes. ${ }^{12} 13$

The magnitude of the overall decline in healthcare use is similar to related work in Addis Ababa ${ }^{14}$ and also work from other parts of the country ${ }^{29}{ }^{30}$ but substantially higher as compared with other SSA African countries. ${ }^{26}$ This is perhaps not surprising as the current sample was designed to represent the most acutely affected regions of the country, with a majority of the sample coming from Addis Ababa. Thus, the estimates presented here should be viewed as an upper bound of the effect of COVID-19 on access to healthcare services in the country. Finally, while considerable efforts were made to check the completeness of the data obtained from the HMIS, health facility records may not always be complete. If such incompleteness is caused by the pandemic itself and thus not random, for instance, if the burden on clinics led to less-than-ideal record keeping then we may overestimate the adverse effects of the pandemic. We examined the number of missing values for each healthcare service 
for the 2-year period. For overall outpatient there were no missing values. For the individual components, there is no clear pattern. For instance, missing values in ANC show an increase in the corona-affected months, however, for delivery and abortions there is no such effect (see online supplemental figure A1).

Overall, the consistency of the results presented here as compared with other work on Ethiopia ${ }^{1429}$ enhances the credibility of the HMIS data. Taken together the results support the idea that despite the sharp decline in overall use of health services, even in the most acutely affected parts of the country, Ethiopia has been able to protect the use of a number of essential maternal and child healthcare services.

How has this been achieved? While exploratory, we find that recognition of the importance of maintaining 'important patient care' has been articulated in the country's COVID-19 management handbook ${ }^{34}$ and by its political leadership. ${ }^{35}$ Through mass media, consistent efforts have been made to communicate that public health facilities are prepared and are able to offer a safe environment for continued and safe use of health services. ${ }^{35}$ The pattern of a decline followed by a return to prepandemic levels of MCH use in May and June 2020, highlights, both, the resilience and responsiveness of the healthcare system and the increase in confidence among healthcare users. Guidelines on preparing health facilities to deal with provision of services during the pandemic were rapidly established, ${ }^{34}$ infection prevention measures were systematically implemented by health facilities ${ }^{29}$ and the delivery mode for some services was altered (from indoor buildings to outdoor tents; more frequent delivery of services in smaller groups). As shown in online supplemental tables $\mathrm{A} 2$ and A3, increased provision and use of PPE-a key concern driving health worker absenteeism-was rapidly achieved and while health worker absenteeism increased during this time period, at 7\%, it remained low. In short, immediate policy interventions and rapid facility-level implementation helped protect essential health services.

A recent brief reviews Ethiopia's policies to maintain essential health services in the time of COVID-19 and argues that the approach does not call for substantive changes but is based on adaptations designed to strengthen the health system. ${ }^{36}$ The brief goes on to argue that 'there is limited evidence on the relative effectiveness of this approach to maintain services during COVID-19'. The results presented in this paper along with the existing work on Ethiopia suggests that the approach has been successful. However, underlining the arguments made in the brief, additional research is clearly needed. This includes, among others, analysis of a longer time period, wider geography, but most importantly, a deeper exploration of the adaptations and interventions used in the country to safeguard the use of essential MCH services. Finally, the results presented here apply to Ethiopia and more research is needed to explain differences across countries when it comes to $\mathrm{MCH}$ service provision during the pandemic. ${ }^{26}$

\section{CONCLUSION}

Simulation-based studies ${ }^{16} 1719$ have provided disconcerting figures of the negative consequences of the disruption of MCH services and increased food insecurity on maternal and child mortality. At least from the perspective of health service disruptions, the results presented here along with those from other parts of Ethiopia and for a set of other countries in $\mathrm{SSA}^{26}$ yields a more optimistic picture. However, these patterns are by no mean universal. ${ }^{27}{ }^{28}$ In the case of Ethiopia, warnings to protect essential healthcare services, especially $\mathrm{MCH}$ seem to have been heeded and despite resource constraints, the country has successfully adapted and managed to protect the provision of essential healthcare services. While this is promising, there are MCH services such as PMTCT and IMNCI which have seen more sustained declines. Furthermore, there is no space for complacency as vaccination rates remain low and the virus continues to spread in rural parts of Ethiopia and SSA. Sustained efforts at maintaining balanced healthcare provision need to continue.

Contributors ZS: conceptualisation, survey design, writing-original draft, project administration, funding acquisition; AM: data collection, data curation, conceptualisation, methodology, formal analysis, investigation, writing-original draft; GA: data collection, survey design, conceptualisation, writing-review and editing; MR: methodology, writing-review and editing, funding acquisition; ASB: conceptualisation, funding acquisition, writing-original draft, guarantor.

Funding This work was supported by D.P. Hoijer Fonds, Erasmus Trustfonds, Erasmus University Rotterdam, The Netherlands. Award/grant number is not applicable.

Competing interests None declared.

Patient consent for publication Not applicable.

Ethics approval Ethics approval (Ethics 2020-24) was provided by the Research Ethics Committee of the International Institute of Social Studies, Erasmus University Rotterdam.

Provenance and peer review Not commissioned; externally peer reviewed.

Data availability statement Data are available on reasonable request. The complete data set used for this study will be uploaded in a public repository on acceptance.

Supplemental material This content has been supplied by the author(s). It has not been vetted by BMJ Publishing Group Limited (BMJ) and may not have been peer-reviewed. Any opinions or recommendations discussed are solely those of the author(s) and are not endorsed by BMJ. BMJ disclaims all liability and responsibility arising from any reliance placed on the content. Where the content includes any translated material, BMJ does not warrant the accuracy and reliability of the translations (including but not limited to local regulations, clinical guidelines, terminology, drug names and drug dosages), and is not responsible for any error and/or omissions arising from translation and adaptation or otherwise.

Open access This is an open access article distributed in accordance with the Creative Commons Attribution Non Commercial (CC BY-NC 4.0) license, which permits others to distribute, remix, adapt, build upon this work non-commercially, and license their derivative works on different terms, provided the original work is properly cited, appropriate credit is given, any changes made indicated, and the use is non-commercial. See: http://creativecommons.org/licenses/by-nc/4.0/.

ORCID iD

Arjun S Bedi http://orcid.org/0000-0001-5659-6569

\section{REFERENCES}

$1 \mathrm{FMoH}$. Health and health related indicators 1994 E.C (2001/02), 2001. Available: https://e-library.moh.gov.et/library/wp-content/ 
uploads/2021/07/Health-and-Health-Related-Indicators-1994-E.C. pdf [Accessed 06 Aug 2021].

$2 \mathrm{FMoH}$. Health and health related indicators $2011 \mathrm{EFY}(2018 / 19)$, 2019. Available: https://e-library.moh.gov.et/library/wp-content/ uploads/2021/07/Health-and-Health-Related-Indicators-2011.pdf [Accessed 07 Aug 2021].

3 World Bank. Current health expenditure per capital-Ethiopia, 2021. Available: https://data.worldbank.org/indicator/SH.XPD.CHEX.PC. CD?locations=ET [Accessed 06 Aug 2021].

$4 \mathrm{FMoH}$. Health and health related indicators 1992 E.C (2001/02), 2000. Available: https://e-library.moh.gov.et/library/wp-content/ uploads/2021/07/Health-and-Health-Related-Indicators-1992-E.C. pdf [Accessed 07 Aug 2021].

5 NPC. Growth and transformation plan II (GTP-II). Addis Ababa: National Planning Commission, 2016.

6 Banteyerga $\mathrm{H}$. Ethiopia's health extension program: improving health through community involvement. MEDICC Rev 2011;13:46-9.

7 Doherty T, Rohde S, Besada D, et al. Reduction in child mortality in Ethiopia: analysis of data from demographic and health surveys. $J$ Glob Health 2016;6:020401.

8 Ruducha J, Mann C, Singh NS, et al. How Ethiopia achieved millennium development goal 4 through multisectoral interventions: a countdown to 2015 case study. Lancet Glob Health 2017;5:e1142-51.

9 Wang H, Roman T, Gandham NVR. Ethiopia health extension program: an institutionalized community approach for universal health coverage. Washington, DC: World Bank, 2016.

10 Rieger M, Wagner N, Mebratie A, et al. The impact of the Ethiopian health extension program and health development army on maternal mortality: a synthetic control approach. Soc Sci Med 2019;232:374-81.

11 Assefa Y, Hill PS, Gilks CF, et al. Primary health care contributions to universal health coverage, Ethiopia. Bull World Health Organ 2020;98:894-905.

12 Shigute Z, Mebratie AD, Alemu G, et al. COVID-19 and balance in access to health care in Ethiopia. Clin Epidemiol Glob Health 2021;9:1.

13 Estifanos AS, Kazmi K, Morris SK. Could COVID-19 reverse the modest gains made in newborn health in Ethiopia? Matern Child Health J 2021;25:849-54.

14 Ayele W, Biruk E, Kifle A. Patterns of essential health services utilization and routine health information management during Covid-19 pandemic at primary health service delivery point Addis Ababa, Ethiopia. Ethiop J of Health Dev 2021;35:91-7.

15 Zewudie A, Regasa T, Kebede O, et al. Healthcare professionals' willingness and preparedness to work during COVID-19 in selected hospitals of Southwest Ethiopia. Risk Manag Healthc Policy 2021;14:391-404.

16 Roberton T, Carter ED, Chou VB, et al. Early estimates of the indirect effects of the COVID-19 pandemic on maternal and child mortality in low-income and middle-income countries: a modelling study. Lancet Glob Health 2020;8:e901-8.

17 Church K, Gassner J, Elliott M. Reproductive health under COVID-19 - challenges of responding in a global crisis. Sex Reprod Health Matters 2020;28:1773163-3.

18 Assefa N, Sié A, Wang D, et al. Reported barriers to healthcare access and service disruptions caused by COVID-19 in Burkina Faso, Ethiopia, and Nigeria: a telephone survey. Am J Trop Med Hyg 2021;105:323-30.
19 Yigezu A, Mirkuzie AH, Misganaw A. The indirect impact of COVID-19 pandemic on maternal and child mortality in Ethiopia: a modelling study, 2020. Available: https://ssrn.com/abstract=3694748

20 Blanchet K, Alwan A, Antoine C, et al. Protecting essential health services in low-income and middle-income countries and humanitarian settings while responding to the COVID-19 pandemic. BMJ Glob Health 2020;5:e003675.

21 Ferreira ALCG, Correa MSM, Pedrosa EN, et al. Does the COVID-19 pandemic impact reproductive health? Rev Bras Ginecol Obstet 2020;42:774-5.

22 Graham WJ, Afolabi B, Benova L, et al. Protecting hard-won gains for mothers and newborns in low-income and middle-income countries in the face of COVID-19: call for a service safety net. BMJ Glob Health 2020;5:e002754.

23 Headey D, Heidkamp R, Osendarp S, et al. Impacts of COVID-19 on childhood malnutrition and nutrition-related mortality. Lancet 2020;396:519-21.

24 McLean M, Abuelaish I. Access to reproductive health care services in countries of conflict: the double impact of conflict and COVID-19. Med Confl Surviv 2020;36:283-91.

25 Okereke M, Ukor NA, Adebisi YA, et al. Impact of COVID-19 on access to healthcare in low- and middle-income countries: current evidence and future recommendations. Int J Health Plann Manage 2021;36:13-17.

26 Shapira G, Ahmed T, Drouard SHP, et al. Disruptions in maternal and child health service utilization during COVID-19: analysis from eight sub-Saharan African countries. Health Policy Plan 2021;36:1140-51.

27 Wanyana D, Wong R, Hakizimana D. Rapid assessment on the utilization of maternal and child health services during COVID-19 in Rwanda. Public Health Action 2021;11:12-21.

28 Jensen C, McKerrow NH. Child health services during a COVID-19 outbreak in KwaZulu-Natal Province, South Africa. S Afr Med J 2020:13185.

29 Workicho A, Kershaw MJ, Berhanu L, et al. Essential Health and Nutrition Service Provision during the COVID-19 Pandemic: Lessons from Select Ethiopian Woredas. Curr Dev Nutr 2021;5:nzab024.

30 Kassie A, Wale A, Yismaw W. Impact of coronavirus Diseases-2019 (COVID-19) on utilization and outcome of reproductive, maternal, and newborn health services at governmental health facilities in South West Ethiopia, 2020: comparative cross-sectional study. Int $J$ Womens Health 2021;13:479-88.

31 CSA. Population projections for Ethiopia 2007-2037. Addis Ababa: Central Statistical Agency, 2013.

32 PHEOC. COVID-19 pandemic preparedness and response in Ethiopia. National public health emergency operation center COVID-19 Weekly bulletin 16, 2020. Available: https://www.ephi.gov. et/images/novel_coronavirus/EPHI_PHEOC_COVID-19_Weekly-_ bulletin_16_English_08172020.pdf

33 Polgreen PM, Polgreen EL. Infectious diseases, weather, and climate. Clin Infect Dis 2018;66:815-7.

$34 \mathrm{FMoH}$. National comprehensive COVID-19 management Handbook. Addis Ababa: $\mathrm{FMoH}, 2020$.

35 GBCHealth, 2020. Available: https://gbchealth.org/discussion-withdr-lia-tadesse-ethiopias-fight-against-covid-19/ [Accessed $31 \mathrm{Jul}$ 2021].

36 PATH. RMNCAYH-N Services During COVID-19: A spotlight on Ethiopia's policy responses to maintain and adapt essential health services 2021. 